Research Article

\title{
Restoring Force Model Research on Joint of Circular Tubed Steel-Reinforced Concrete Column
}

\author{
Yan Dai $\mathbb{D}^{1},{ }^{1}$ Shaofeng Nie, ${ }^{2}$ Tianhua Zhou, ${ }^{2}$ Yichun $\mathrm{Xu}^{3}$ and Jingrong Peng ${ }^{1}$ \\ ${ }^{1}$ Shaanxi Key Laboratory of Safety and Durability of Concrete Structures, Xijing University, Xi'an 710123, China \\ ${ }^{2}$ School of Civil Engineering, Chang'an University, Xi'an 710061, China \\ ${ }^{3}$ Ping an Construction Group Co., Ltd, Hangzhou 310000, China \\ Correspondence should be addressed to Yan Dai; daiyan@xijing.edu.cn
}

Received 29 July 2021; Accepted 28 August 2021; Published 17 September 2021

Academic Editor: Jingxuan Wang

Copyright ( 2021 Yan Dai et al. This is an open access article distributed under the Creative Commons Attribution License, which permits unrestricted use, distribution, and reproduction in any medium, provided the original work is properly cited.

\begin{abstract}
In this paper, two joints of circular tubed steel-reinforced concrete (CTSRC) column were designed. The load-displacement hysteretic curve and skeleton curve of this new type of joint are obtained by the pseudostatic test under low cycle cyclic load on the top of the column. The results show that this new type of joint has good seismic energy dissipation performance. On the basis of the test, a three-fold skeleton curve model considering three characteristic points of yield, limit, and failure is proposed, and the expression of skeleton curve model is given. The load and unload stiffness degradation law of specimens under reciprocating load is studied, and the expression of stiffness degradation law is given. The hysteresis law of the new type joint specimens is described in detail. The validity of the model is verified by comparing the experimental curve with the model curve. The model can be used in the elastic-plastic seismic time-history analysis on the joint of circular tubed steel-reinforced concrete (CTSRC) column.
\end{abstract}

\section{Introduction}

The restoring force model is used to explain the relationship between the load and displacement of the structure under repeated load, which can reflect the ability of the structure to recover the original deformation after unloading. In the study of the seismic performance of the structure, the restoring force model is the basis of the seismic stress analysis, which mainly reflects the performance of the structure, such as energy consumption, ductility, strength, and stiffness. Since 1940s, seismic engineering has carried out extensive research on structural restoring force curve modeling. Researchers have proposed the following models: the Ramberg-Osgood model $[1,2]$ proposed by Jennings is shown in Figure 1(a). The model is mainly used to describe the restoring force characteristics of metal materials and also used in soil and reinforced concrete flexural structures; as shown in Figure 1(b), Clough [3] proposed a relatively early model considering the degradation of loading and unloading stiffness, which is mainly proposed as the restoring force characteristic model of reinforced concrete flexural members. Takeda et al. [4] proposed a three-fold line stiffness degradation model, as shown in Figure 1(c). The model is obtained through the low cycle reciprocating loading test of reinforced concrete columns and based on the test results. Because it has one more crack point than the two-fold line model, it can more truly reflect the mechanical characteristics of steel reinforced concrete structures.

In recent years, a series of research studies have been carried out on the load displacement relationship models of various new structures under repeated loads. Yan et al. established the hysteretic model of the joints between steel reinforced ultrahigh strength concrete columns and steel reinforced concrete beams and put forward the quantitative method of seismic damage and attenuation coefficient [5]. Zhang and Han proposed a prediction model for cyclic lateral load deformation response of RC columns subjected to axial compression and cyclic shear; comparison between the predicted cyclic response and experimental results indicates that the proposed model can predict the observed hysteretic response of flexureshear critical RC columns well [6]. Yuka and Hideki proposed a hysteretic model of $\mathrm{H}$-beam considering 


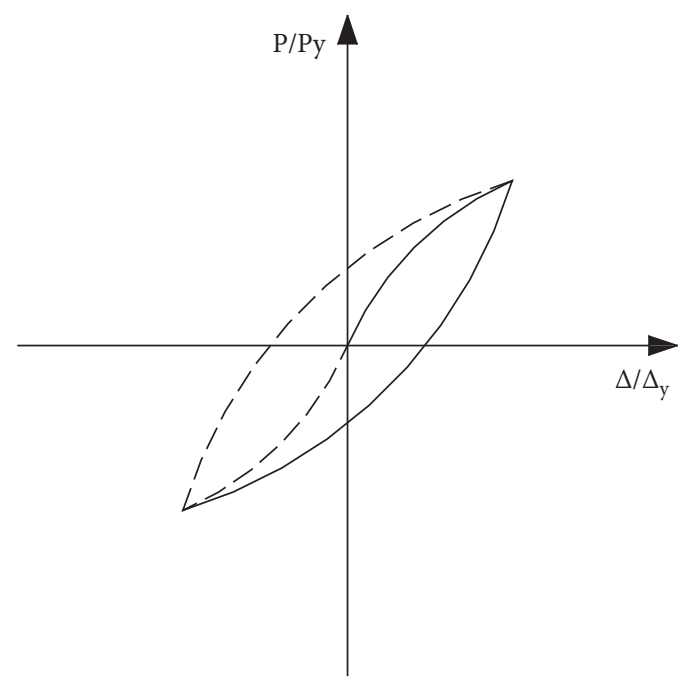

(a)

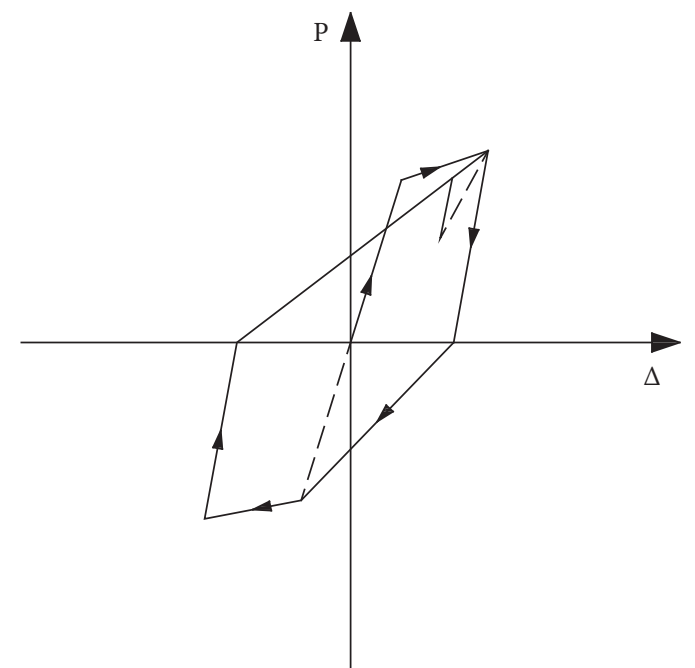

(b)

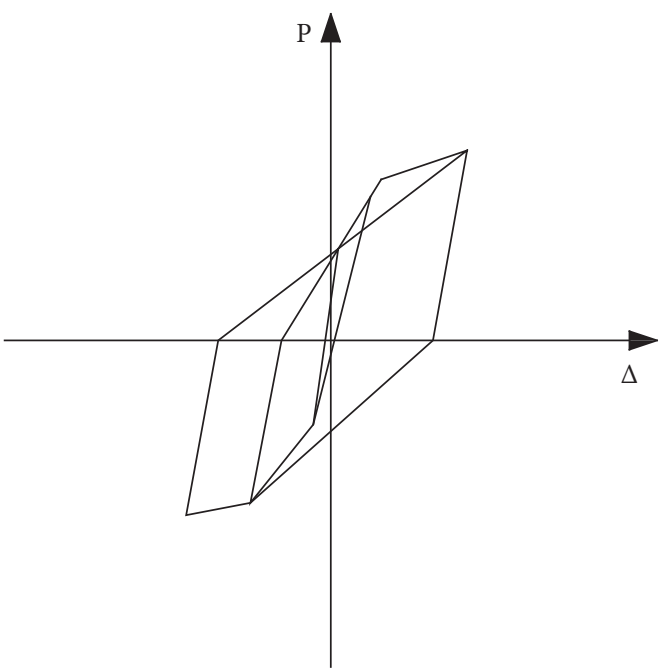

(c)

Figure 1: Common restoring force models. (a) Ramberg-Osgood model. (b) Clough degenerate bilinear model. (c) Takeda three-fold line stiffness degradation model.

slenderness ratio and also proposed a hysteretic model suitable for uniform moment and antisymmetric moment [7]. Zhang et al. studied the hysteretic behavior of six glass bead insulation concrete frame columns (GIC columns) and one ordinary concrete frame column; the results can provide theoretical basis for elastic-plastic analysis of GIC column under earthquake action [8]. Hao et al. proposed an effective method to calculate the monotone curve and hysteretic curve of H-beam under bending moment. The accuracy of predicting the hysteretic behavior of $\mathrm{H}$-beam is verified by comparing with the numerical results [9]. Wang et al. carried out nonlinear time-history analysis on a new type of energy dissipation joint of bamboo steel hybrid frame and proposed the joint restoring force model with the best performance [10]. Li et al. proposed an innovative method to consider the influence of dynamic effects and degradation on seismic performance analysis of reinforced concrete frame structures [11]. Xie et al. carried out quasistatic tests on three $1 / 10$ scale pier specimens and established the hysteretic model of prefabricated pier, which was in good agreement with the test results [12]. Wu et al. studied the restoring force model of h-steel-reinforced concrete column composite joints (hereinafter referred to as MPSC joints), which has high accuracy and can be used for the design of MPSC joints [13]. Song et al. designed ten PVC-CFRP confined concrete column-ring beam interior joints (PCCC-RBIJs) and one PVC confined concrete column-ring beam interior joint (control interior joint) and studied their restoring force models [14]. Ni et al. conducted in-depth experimental research on the seismic performance of high-strength reinforced concrete shear walls and proposed a restoring force model of high-strength reinforced concrete shear walls composed of skeleton curves and a group of empirical hysteretic laws [15]. 
The CTSRC column is a new type of composite structure. The relative research [16-18] shows that it has high compressive and shear capacity and superior seismic performance and can make full use of the performance of high-strength materials. On this basis, the authors put forward a new type joint of CTSRC column [19-21]. By applying low-cycle reciprocating load on the top of the column, the load displacement relationship under reciprocating load is studied.

There are mainly two methods to analyze and study the restoring force model: one is based on the basic research of the steel bar, steel tube, and concrete and the bond relationship between steel bar and concrete, steel tube and concrete, to obtain the idealized material constitutive model and structural strain model and to obtain the hysteretic curve of the restoring force relationship by the iterative method; the second is to simulate the test results directly $[22,23]$. In this paper, the second method is used to study the restoring force characteristics of the new type joint based on the quasistatic test and the measured hysteretic curves. The restoring force model suitable for the new type joint is established, which provides the basis for the future elastic-plastic timehistory analysis of structures.

\section{Test Preparation and Results}

2.1. Specimen Design and Loading Scheme. In this paper, two full-scale joints in frame structure were designed. The specimen numbers are $\mathrm{SH}-1$ and $\mathrm{SH}-2$. The main differences between the two specimens are the reinforcement ratio of ring beam and the form of ring beam. The specimen numbers and parameters are shown in Table 1.

The height and width of the two specimens are $4375.0 \mathrm{~mm}$ and $3370.0 \mathrm{~mm}$, respectively. The outer diameter of circular steel tube is $400.0 \mathrm{~mm}$. In order to ensure that the circular steel tube does not bear the longitudinal load, the circular steel tube was disconnected in the joint area and a $15.0 \mathrm{~mm}$ ring opening is reserved from the upper and lower edges of the concrete ring beam. The other structures and dimensions are shown in Figure 2 (taking SH-1 specimen as an example).

The quasistatic test is generally divided into column end loading and beam end loading. Because the secondorder effect of gravity can be considered in the column end loading [24], the column-end-loading mode was adopted in this paper: First, the vertical load is gradually applied to $1500 \mathrm{kN}$ by the jack at the top of the column in three stages and the load lasts for several minutes; second, the MTS servoactuator is used to apply the low-cycle reciprocating load on the top of the column, and the load control is used before yielding. After yielding, the load is carried out according to the multiple of the yield displacement of the top of the column, and each cycle is carried out three times until the specimen is damaged or the horizontal load of the top of the column drops below $85 \%$ of its peak load. The test device diagram and loading diagram are shown in Figure 3.
2.2. Test Result. The load-displacement hysteretic curves of the two specimens are shown in Figure 4. It can be seen from the figure that the hysteretic curves of the two specimens are full, showing a very good seismic energy dissipation performance.

\section{Establishment of the Restoring Force Model}

The restoring force model for nonlinear analysis consists of three parts: skeleton curve, stiffness degradation law, and hysteretic characteristics. The results show that a reasonable restoring force model can reflect the hysteretic stress characteristics of actual structure or component and be simple and practical within the acceptable limit, so as to facilitate the effective elastic-plastic response analysis.

3.1. Skeleton Curve Model. The skeleton curve determines the characteristic points of the restoring force model, which is the connecting line of the characteristic points in the $1 / 4$ hysteretic curve. In this test, the characteristic point loads and displacements of the two joint specimens are different. In order to facilitate the comparison, the skeleton curves of the two specimens are first treated as dimensionless. The formula is as follows:

$$
\begin{gathered}
\frac{ \pm P}{\left| \pm P_{\max }\right|}, \\
\frac{ \pm \Delta}{\left| \pm \Delta_{\max }\right|},
\end{gathered}
$$

where $\pm \Delta P_{\max }$ is the maximum positive and reverse load on the top of the column and $\pm \Delta_{\max }$ is the displacement corresponding to the maximum positive and reverse load. The results are shown in Table 2, and the dimensionless skeleton curves of specimens are obtained, as shown in Figure 5.

It can be seen from the above figure that the skeleton curves of the two specimens after dimensionless treatment still show their own regular characteristics. By analyzing the hysteretic curves and dimensionless skeleton curves of specimens, it can be seen that the skeleton curves of the two specimens can be approximately fitted with a broken line. Therefore, the skeleton curve in this paper adopts the form of three broken lines considering yield load, ultimate load, and stiffness degradation and is simulated by the connecting line of three characteristic points. The three characteristic points are yield point, ultimate load point, and failure point (when the bearing capacity decreases to 0.85 times of the ultimate load point).

According to the dimensionless values of the characteristic points of the specimens in Table 2, the coordinates of the characteristic points corresponding to the specimens SH-1 and SH-2 are given as follows: $\left(-\Delta_{u} /\left|-\Delta_{\max }\right|,-P_{u} /\right.$ $\left.\left|-P_{\max }\right|\right),(1,1),\left(-\Delta_{y} /\left|-\Delta_{\max }\right|,-P_{y} /\left|-P_{\max }\right|\right),(0,0),\left(+\Delta_{y} /\right.$ $\left.+\Delta_{\max }+P_{y} /+P_{\max }\right),(1,1)$, and $\left(+\Delta_{u} /+\Delta_{\max },+P_{u} /+P_{\max }\right)$.

Taking these coordinate points as the control points of regression analysis and connecting the characteristic points, the three-fold line skeleton curve model of two specimens can be drawn, as shown in Figure 6. 
TABLE 1: Test piece number and parameter table.

Specimen number Steel ratio (\%) Thickness of circular tube steel pipe (mm) Form of ring beam Reinforcement ratio of ring beam (\%)

SH-1

$\mathrm{SH}-2$

4.19

5.0

Octagon

3.55

Circular 2.05

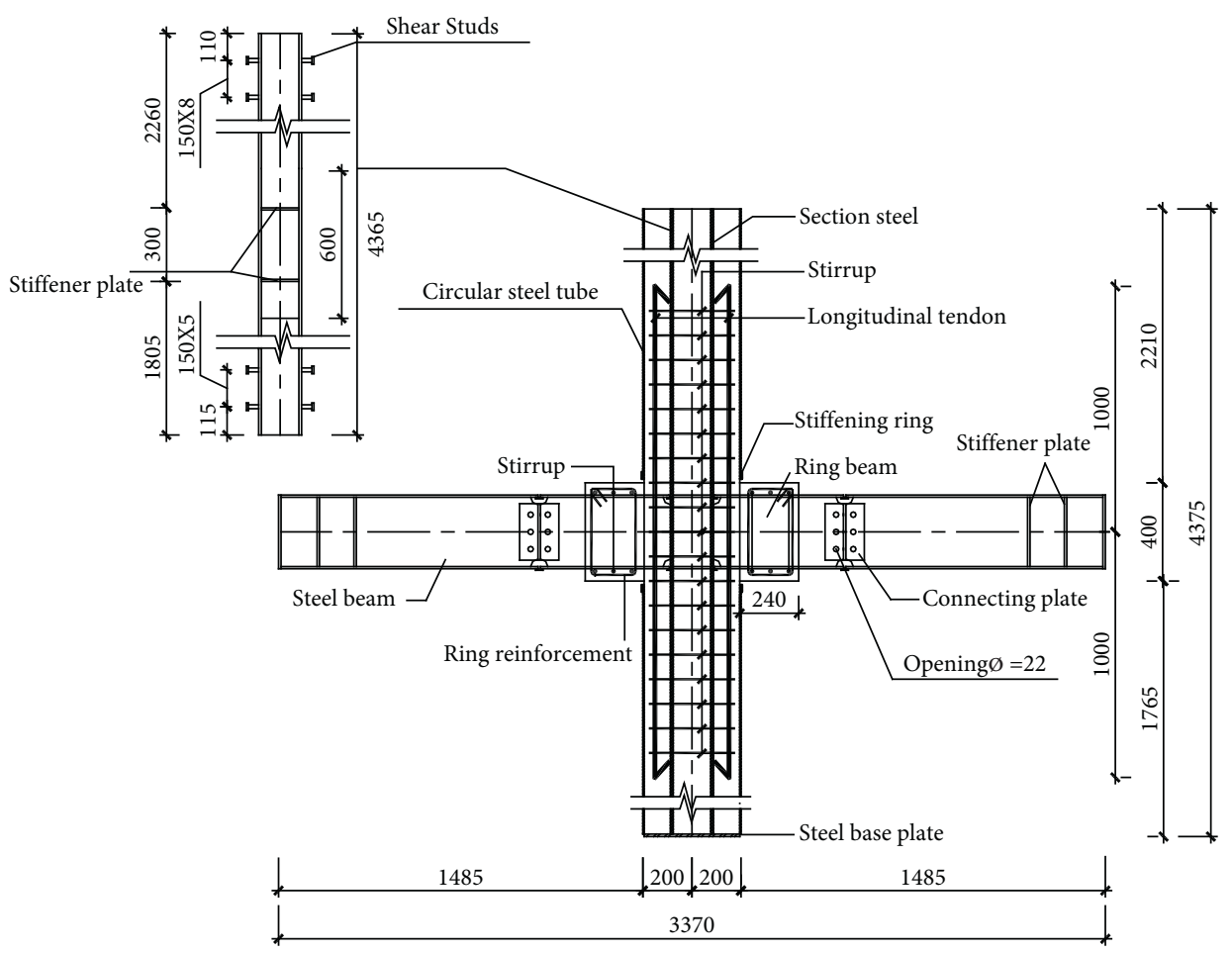

(a)
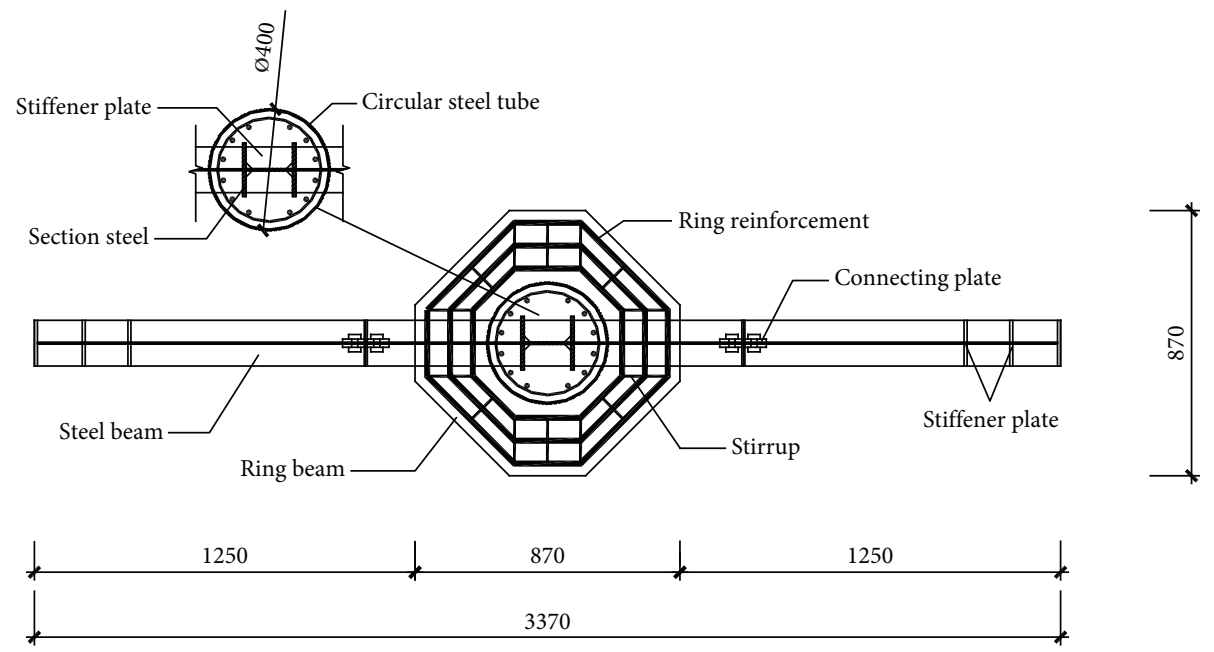

(b)

Figure 2: Structural diagram of the specimen (mm). (a) Elevation. (b) Plan.

In Figure 6, the control points $\mathrm{A}$ and $\mathrm{A}$ ' are the positive and reverse yield points, $\mathrm{B}$ and $\mathrm{B}^{\prime}$ are the positive and reverse ultimate load points, and $\mathrm{C}$ and $\mathrm{C}^{\prime}$ are the positive and reverse failure points. According to the control points on the skeleton curve, the three-fold line skeleton curve expression of the two specimens can be obtained, as shown in Table 3.
3.2. Stiffness Degradation Law. According to the hysteretic curve and skeleton curve, the loading and unloading stiffness of the specimen has a certain degree of degradation. The following is the degradation law of loading and unloading stiffness of the specimen under repeated loading [25]. As shown in Figure 7, K1 is the positive unloading stiffness, K2 


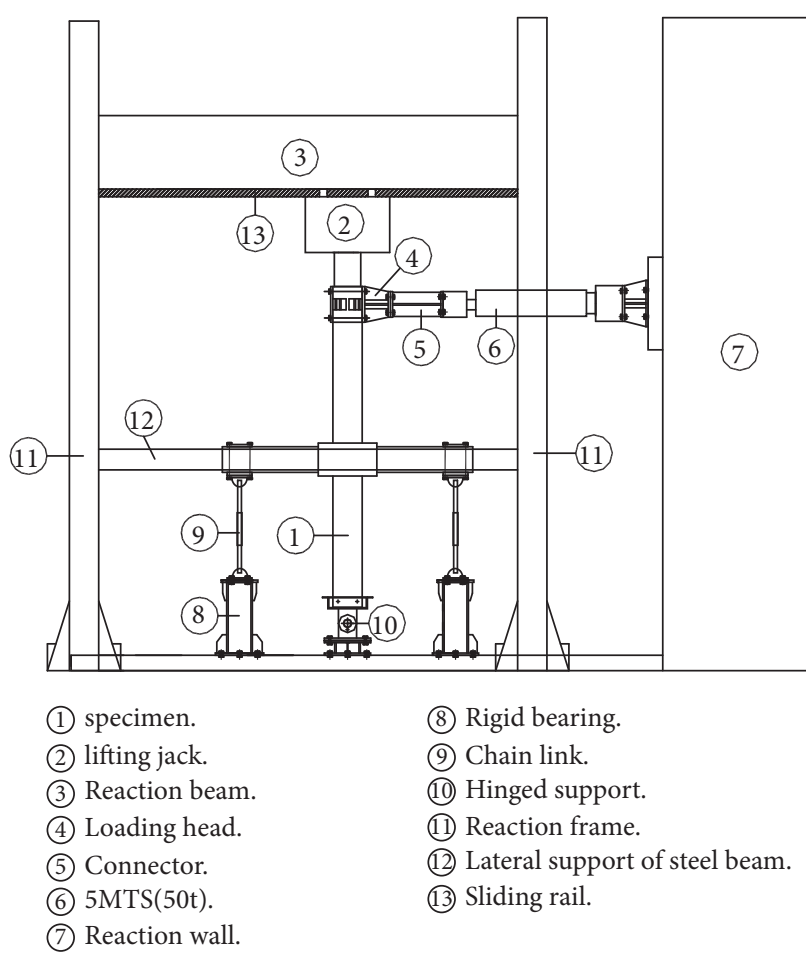

(a)

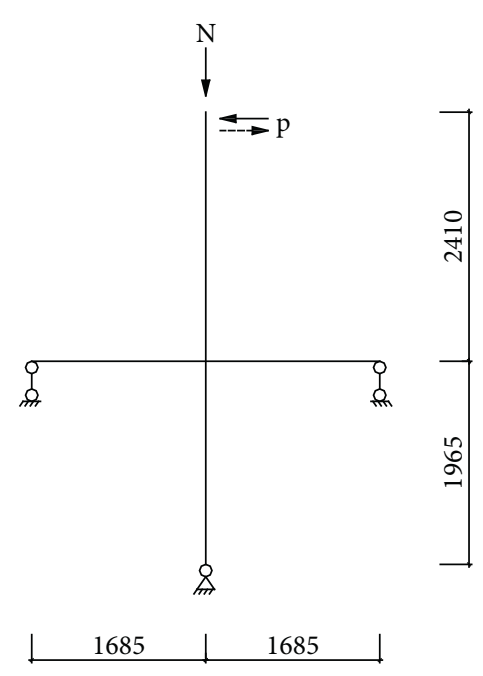

Figure 3: (a) Test device diagram (1) specimen, (2) lifting jack, (3) Reaction beam, (4) Loading head, (5) Connector, (6) 5MTS(50t), (7) Reaction wall, (8) Rigid bearing, (9) Chain link, (10) Hinged support, (11) Reaction frame, (12) Lateral support of steel beam, (13) Sliding rail). (b) Loading diagram.

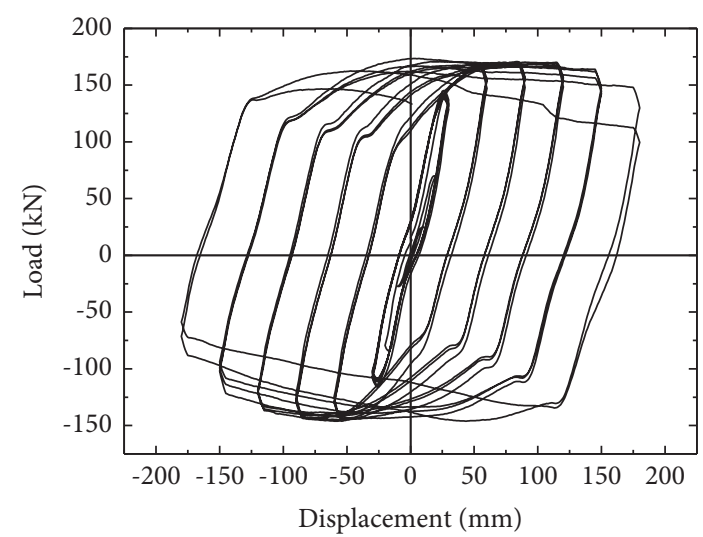

(a)

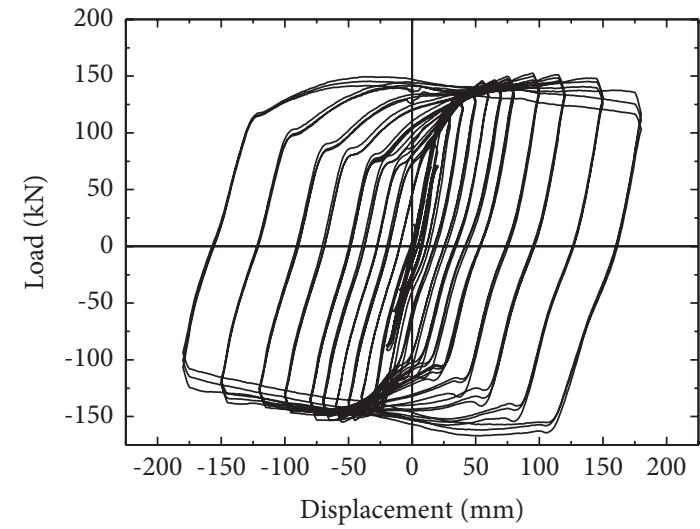

(b)

Figure 4: Load-displacement hysteretic curve of specimen column top. (a) SH-1. (b) SH-2.

TABLE 2: Dimensionless treatment of characteristic points of skeleton curves.

\begin{tabular}{|c|c|c|c|c|c|c|c|}
\hline & \multirow{2}{*}{ Specimen } & \multicolumn{2}{|c|}{ Yield state } & \multicolumn{2}{|c|}{ Ultimate load state } & \multicolumn{2}{|c|}{ Failure state } \\
\hline & & $P_{y}$ & $\Delta_{y}$ & $P_{\max }$ & $\Delta_{\max }$ & $P_{u}$ & $\Delta_{u}$ \\
\hline \multirow{4}{*}{ SH-1 } & Positive & $155.8 \mathrm{kN}$ & $41.7 \mathrm{~mm}$ & $168.4 \mathrm{kN}$ & $60.0 \mathrm{~mm}$ & $143.4 \mathrm{kN}$ & $178.5 \mathrm{~mm}$ \\
\hline & Dimensionless & 0.93 & 0.69 & 1.00 & 1.00 & 0.85 & 2.98 \\
\hline & Reverse & $127.7 \mathrm{kN}$ & $32.4 \mathrm{~mm}$ & $144.3 \mathrm{kN}$ & $60.0 \mathrm{~mm}$ & $126.9 \mathrm{kN}$ & $154.2 \mathrm{~mm}$ \\
\hline & Dimensionless & 0.89 & 0.54 & 1.00 & 1.00 & 0.88 & 2.57 \\
\hline \multirow{4}{*}{$\mathrm{SH}-2$} & Positive & $131.3 \mathrm{kN}$ & $31.3 \mathrm{~mm}$ & $151.5 \mathrm{kN}$ & $80.0 \mathrm{~mm}$ & $130.4 \mathrm{kN}$ & $180.0 \mathrm{~mm}$ \\
\hline & Dimensionless & 0.87 & 0.39 & 1.00 & 1.00 & 0.86 & 2.25 \\
\hline & Reverse & $120.7 \mathrm{kN}$ & $20.3 \mathrm{~mm}$ & $155.3 \mathrm{kN}$ & $60.0 \mathrm{~mm}$ & $132.8 \mathrm{kN}$ & $157.5 \mathrm{~mm}$ \\
\hline & Dimensionless & 0.78 & 0.34 & 1.00 & 1.00 & 0.86 & 2.92 \\
\hline
\end{tabular}




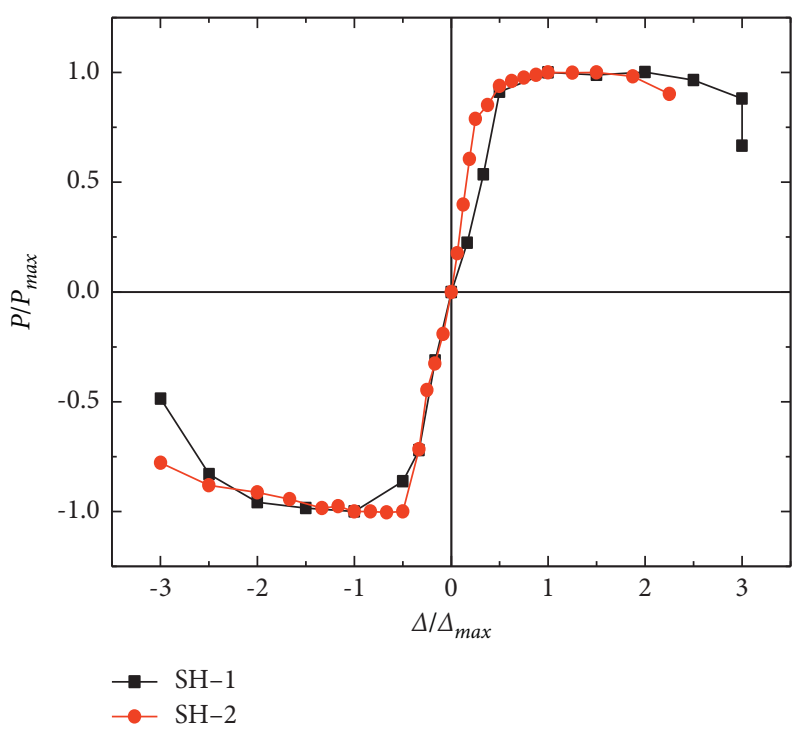

Figure 5: Dimensionless skeleton curves of specimens.

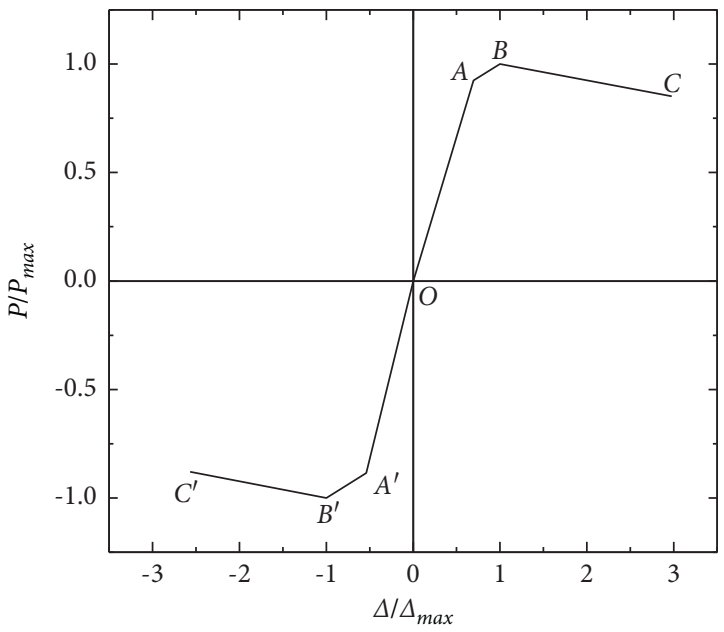

(a)

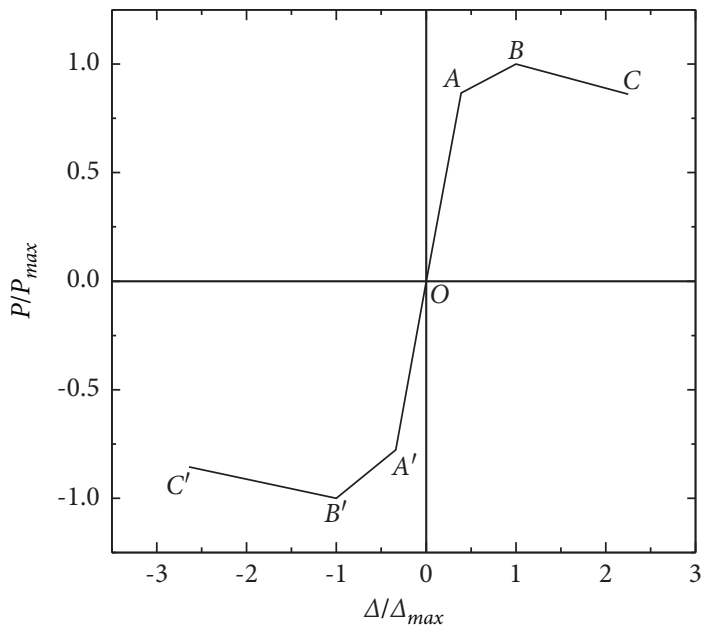

(b)

FIgURE 6: Curve model of three-fold line skeleton of test piece. (a) SH-1. (b) SH-2.

TABLE 3: Three-fold line skeleton curve expression.

\begin{tabular}{lcc}
\hline Line segment & SH-1 & SH-2 \\
\hline$O A$ & $P /+P_{\max }=1.3329\left(\Delta /+\Delta_{\max }\right)$ & $P /+P_{\text {max }}=2.2174\left(\Delta /+\Delta_{\max }\right)$ \\
$A B$ & $P /+P_{\max }=0.2451\left(\Delta /+\Delta_{\max }\right)+0.7549$ & $P /+P_{\max }=0.2184\left(\Delta /+\Delta_{\max }\right)+0.7816$ \\
$B C$ & $P /+P_{\max }=-0.0754\left(\Delta /+\Delta_{\max }\right)+1.0754$ & $P /+P_{\max }=-0.1112\left(\Delta /+\Delta_{\max }\right)+1.1112$ \\
$O A^{\prime}$ & $P /\left|-P_{\max }\right|=1.6419\left(\Delta /\left|-\Delta_{\max }\right|\right)$ & $P /\left|-P_{\max }\right|=2.2988\left(\Delta /\left|-\Delta_{\max }\right|\right)$ \\
$A^{\prime} B^{\prime}$ & $P /\left|-P_{\max }\right|=0.2495\left(\Delta /\left|-\Delta_{\max }\right|\right)-0.7505$ & $P /\left|-P_{\max }\right|=0.3369\left(\Delta /\left|-\Delta_{\max }\right|\right)-0.6631$ \\
$B^{\prime} C^{\prime}$ & $P /\left|-P_{\max }\right|=-0.0772\left(\Delta /\left|-\Delta_{\max }\right|\right)-1.0772$ & $P /\left|-P_{\max }\right|=-0.0893\left(\Delta /\left|-\Delta_{\max }\right|\right)-1.0893$ \\
\hline
\end{tabular}

is the reverse loading stiffness, $\mathrm{K} 3$ is the reverse unloading stiffness, $\mathrm{K} 4$ is the positive loading stiffness, $a$ is the positive unloading point, $b$ is the reverse loading point, $c$ is the reverse unloading point, $d$ is the positive loading point, $\Delta_{1}$ is the displacement corresponding to the positive unloading point $a, \Delta_{2}$ is the residual deformation when positive unloading to zero, $\Delta_{3}$ is the displacement corresponding to the reverse unloading point $c$, and $\Delta_{4}$ is the residual deformation when reverse unloading to zero, and the meanings of other symbols are the same as above.

3.2.1. Degradation Law of Specimen Stiffness under Positive Unloading $\left(K_{1}\right)$. As shown in Figure 7, the slope of line $a b$ is the positive unloading stiffness $K_{1}$. By sorting out the 


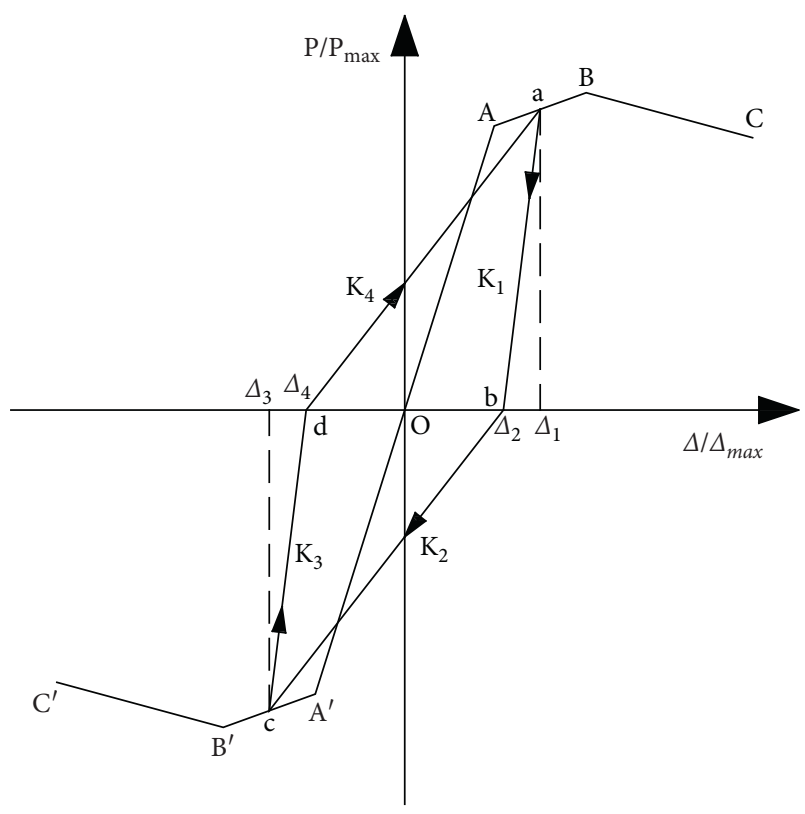

Figure 7: Stiffness degradation law.

hysteretic curve data of two specimens, the slope value of line $a b$ under different displacement amplitudes of each specimen can be obtained, and it can be dimensionless. The abscissa is $\Delta_{1} / \Delta_{\text {max }}$, and the ordinate is $\mathrm{K}_{1} / \mathrm{K}_{0+}$. The scatter diagram of the degradation law of positive unloading stiffness $\left(\mathrm{K}_{1}\right)$ of each specimen can be obtained, where $\Delta_{\max +}$ represents the displacement corresponding to the peak point when the joint specimen is under positive loading. $\mathrm{K}_{0+}$ represents the initial elastic stiffness of the joint under positive loading. After removing the obvious singular points, using the method of nonlinear data fitting, the degradation law curve and its regression formulas of the positive unloading stiffness $\mathrm{K}_{1}$ of each specimen can be obtained, as shown in Figure 8 and equations (2) and (3).

The regression formulas of $\mathrm{K}_{1}$ are as follows:

$$
\begin{aligned}
& \frac{K_{1}}{K_{0}^{+}}=1.221 e^{\left(0.20164 /\left(\Delta_{1} / \Delta_{\max }^{+}\right)+0.16819\right)}, \\
& \frac{K_{1}}{K_{0}^{+}}=1.11917 e^{-\left(\left(\Delta_{1} / \Delta_{\max }^{+}\right) / 0.31645\right)}+1.23644 .
\end{aligned}
$$

\subsubsection{Degradation Law of Specimen Stiffness under Reverse} Loading $\left(K_{2}\right)$. As shown in Figure 7, the slope of line $b c$ is the reverse loading stiffness $K_{2}$. Using the same method as in Section 3.2.1, the degradation law curve and its regression formulas of the reverse loading stiffness $\mathrm{K}_{2}$ of each specimen can be obtained, as shown in Figure 9 and equations (4) and (5).

The regression formulas of $\mathrm{K}_{2}$ are as follows:

$$
\begin{aligned}
& \frac{K_{2}}{K_{0}^{-}}=e^{-1.4838\left(\Delta_{2} / \Delta_{\max }^{+}\right)}, \\
& \frac{K_{2}}{K_{0}^{-}}=e^{0.10061-2.83541\left(\Delta_{2} / \Delta_{\max }^{+}\right)+0.8073\left(\Delta_{2} / \Delta_{\max }^{+}\right)^{2}} .
\end{aligned}
$$

3.2.3. Degradation Law of Specimen Stiffness under Reverse Unloading $\left(K_{3}\right)$. As shown in Figure 7, the slope of line $c d$ is the reverse unloading stiffness $K_{3}$. Using the same method as in Section 3.2.1, the degradation law curve and its regression formulas of the reverse unloading stiffness $\mathrm{K}_{3}$ of each specimen can be obtained, as shown in Figure 10 and equations (6) and (7).

The regression formulas of $\mathrm{K}_{3}$ are as follows:

$$
\begin{aligned}
& \frac{K_{3}}{K_{0}^{-}}=e^{0.57368-0.32551\left(\Delta_{3} / \Delta_{\max }^{-}\right)+0.07056\left(\Delta_{3} / \Delta_{\max }^{-}\right)^{2}}, \\
& \frac{K_{3}}{K_{0}^{-}}=e^{0.61056-0.49113\left(\Delta_{3} / \Delta_{\max }^{-}\right)+0.14038\left(\Delta_{3} / \Delta_{\max }^{-}\right)^{2}} .
\end{aligned}
$$

3.2.4. Degradation Law of Specimen Stiffness under Positive Loading $\left(K_{4}\right)$. As shown in Figure 7 , the slope of line $d a$ is the positive loading stiffness $\mathrm{K}_{4}$. Using the same method as in Section 3.2.1, the degradation law curve and its regression formulas of the positive loading stiffness $\mathrm{K}_{4}$ of each specimen can be obtained, as shown in Figure 11 and equations (8) and (9).

The regression formulas of $\mathrm{K}_{4}$ are as follows:

$$
\begin{aligned}
& \frac{K_{4}}{K_{0}^{+}}=e^{0.30267-1.95449\left(\Delta_{4} / \Delta_{\max }^{-}\right)+0.40772\left(\Delta_{4} / \Delta_{\max }^{-}\right)^{2}}, \\
& \frac{K_{4}}{K_{0}^{+}}=e^{0.28584-1.57987\left(\Delta_{4} / \Delta_{\max }^{-}\right)+0.03819\left(\Delta_{4} / \Delta_{\max }^{-}\right)^{2}} .
\end{aligned}
$$

3.3. Description of Hysteresis Rule. The actual restoring force curve on the joint of CTSRC column is hard to describe, so it is necessary to establish a simplified model which can reflect the actual restoring force characteristics. According to the skeleton curve model and stiffness degradation law, combined with the hysteretic curve, the restoring force model of the specimens was established, as shown in Figure 12.

The hysteresis rule is described as follows:

(1) When the specimen is under positive loading, the relationship between load and displacement develops along the skeleton curve $O A B C$. If the specimen is unloading in the $O A$ section (the positive loading does not yield), the positive loading stiffness does not degenerate and the relationship between load and displacement returns along the $A O$ section (the unloading line is $A O$ ). If the specimen is unloading in the $A B$ section (the positive loading yields), the positive loading stiffness begins to degenerate and the relationship between load and displacement returns along the $a b$ line (the unloading line is $a b$ ). If the specimen is unloading in the $B C$ section (the load has passed the peak point), the relationship between load and displacement returns along $e b$ section (the unloading line is $e b$ ). 


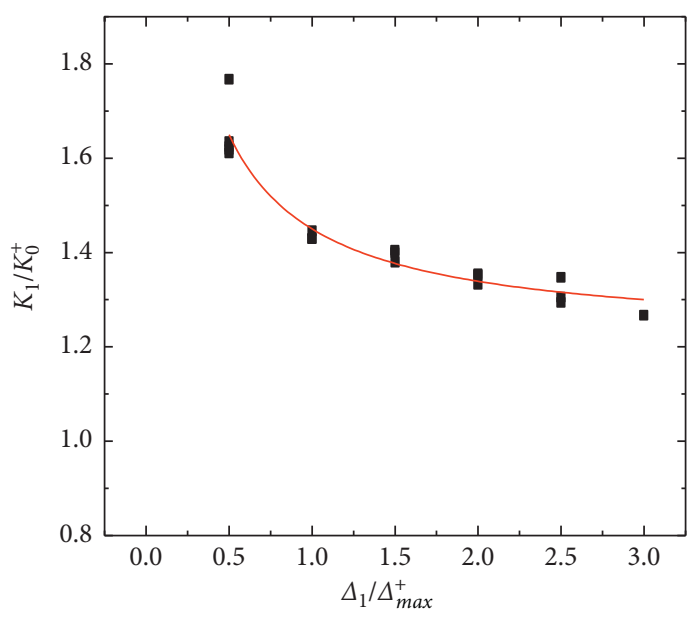

(a)

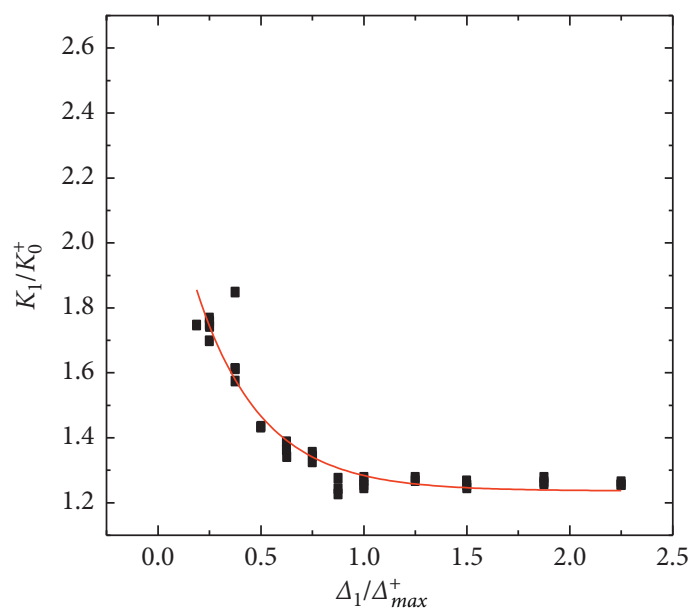

(b)

Figure 8: Regression curve fitting $\left(\mathrm{K}_{1}\right)$. (a) SH-1. (b) SH-2.

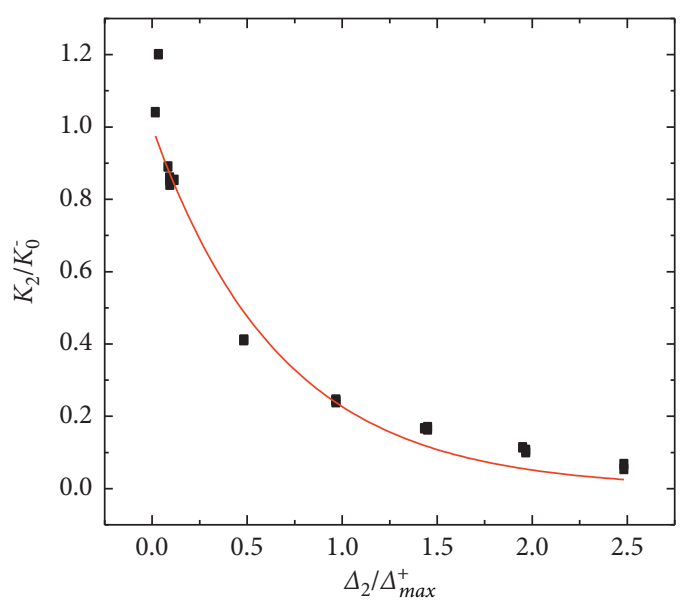

(a)

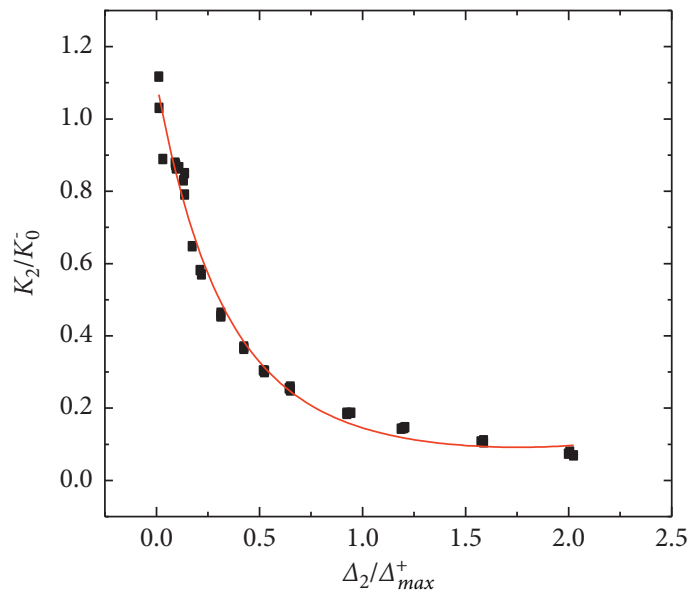

(b)

Figure 9: Regression curve fitting $\left(\mathrm{K}_{2}\right)$. (a) SH-1. (b) SH-2.

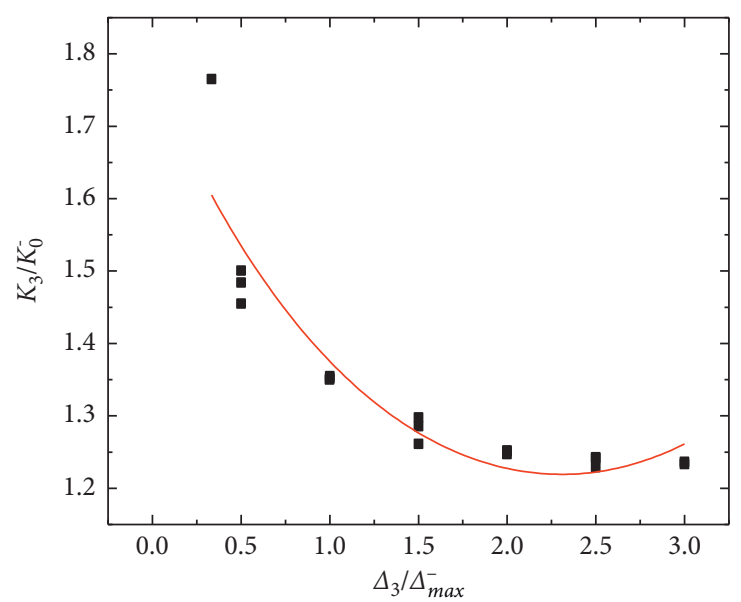

(a)

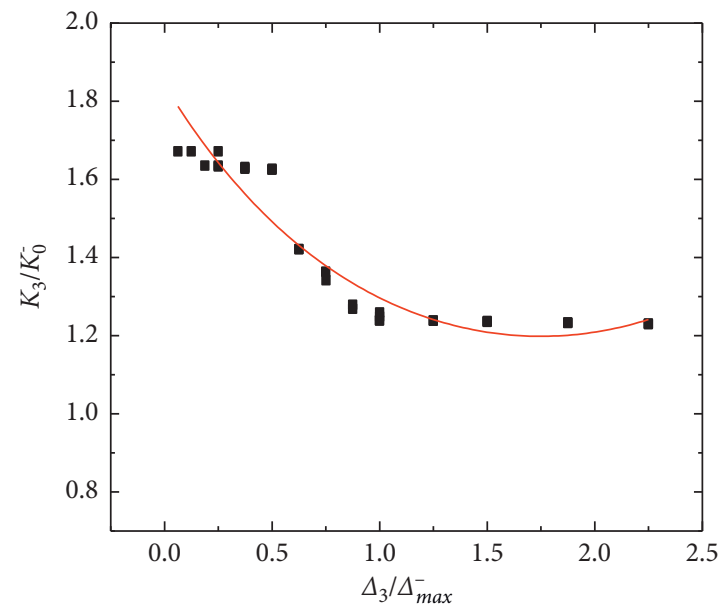

(b)

FIgURE 10: Regression curve fitting $\left(\mathrm{K}_{3}\right)$. (a) SH-1. (b) SH-2. 


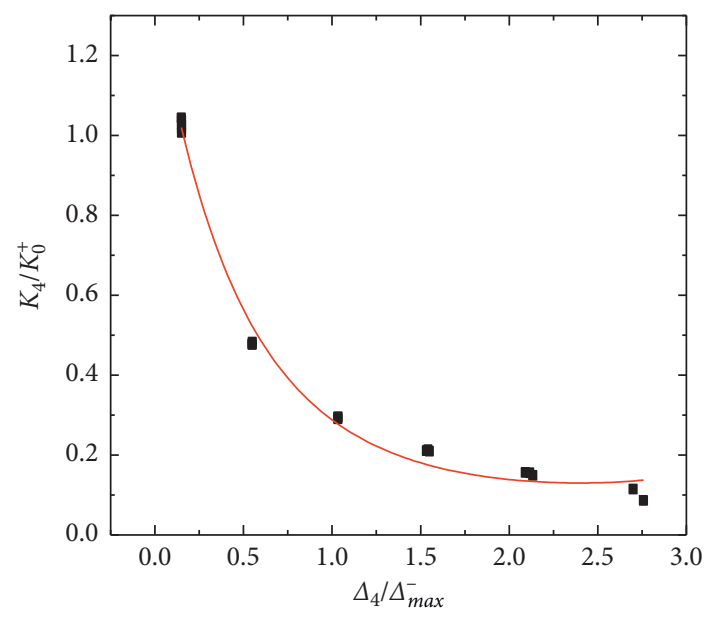

(a)

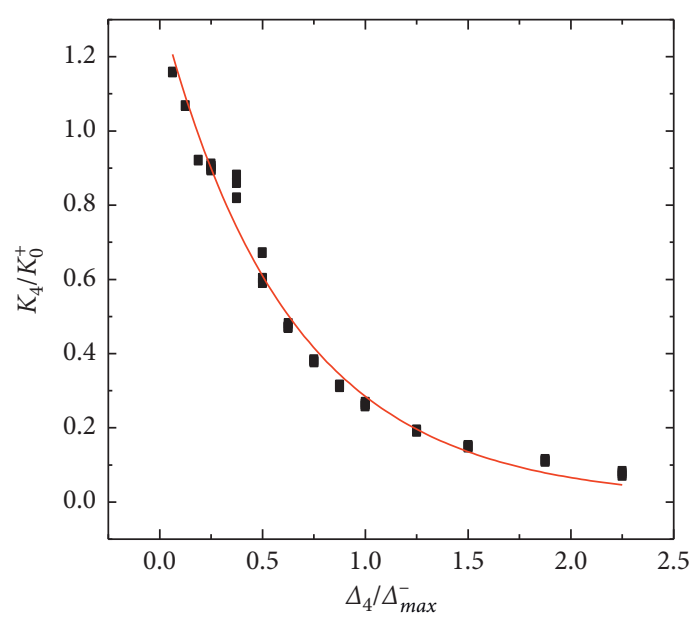

(b)

Figure 11: Regression curve fitting $\left(\mathrm{K}_{4}\right)$. (a) SH-1. (b) SH-2.

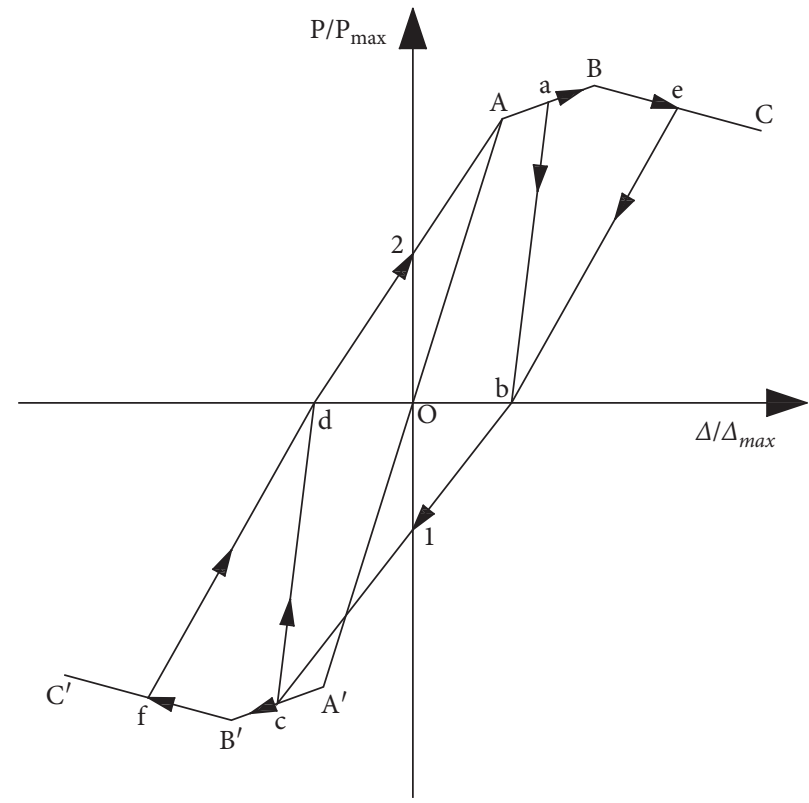

FIgURE 12: Restoring force model.

(2) When the specimen is unloading to $b$ point and then loading reversely, the relationship between load and displacement develops along $b l A^{\prime} B^{\prime} C^{\prime}$. If the specimen is unloading at $1 A^{\prime}$ 'section (the reverse loading does not yield), the reverse loading stiffness does not degenerate and the relationship between load and displacement returns along $A^{\prime} O$ line section (the unloading line is $A^{\prime} O$ ). If the specimen is unloading at $A^{\prime} B^{\prime}$ section (the reverse loading yields), the reverse loading stiffness will degenerate and the relationship between load and displacement returns along section $c d$ (the unloading line is $c d$ ). If the specimen is unloading at $B^{\prime} C^{\prime}$ section (the reverse loading has passed the peak point), the relationship between load and displacement returns along $f d$ section (the unloading line is $f d$ ).
(3) When the specimen is unloading to $d$ point and then loading again, the relationship between load and displacement develops along $d 2 A B C$, and the subsequent loading and unloading is the same as the first loading.

\section{Verification of Resilience Model}

4.1. Verification of Skeleton Curve. The skeleton curve model can be obtained by connecting the feature points in front, and the skeleton curve model is compared with the measured skeleton curve, as shown in Figure 13. It can be seen that the skeleton curve model can better reflect the load displacement variation law of two joint specimens. 


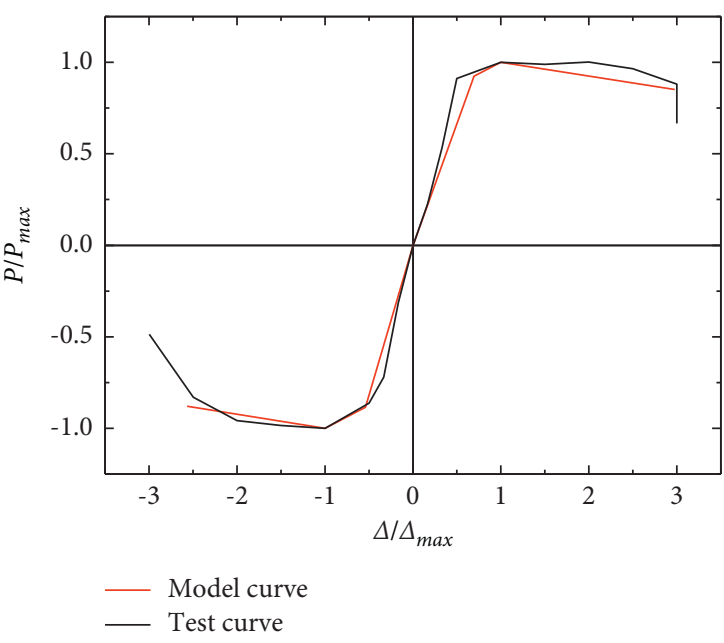

(a)

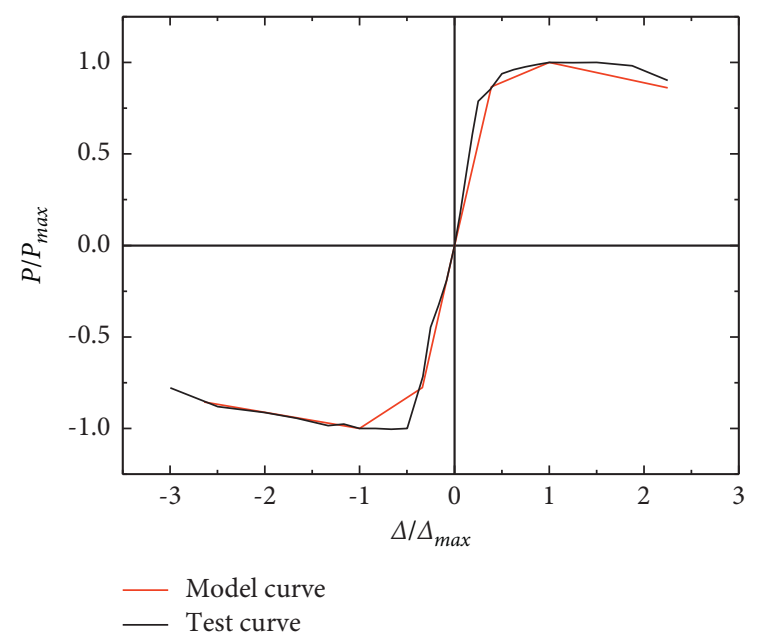

(b)

Figure 13: Comparison between the model curve and test curve. (a) SH-1. (b) SH-2.

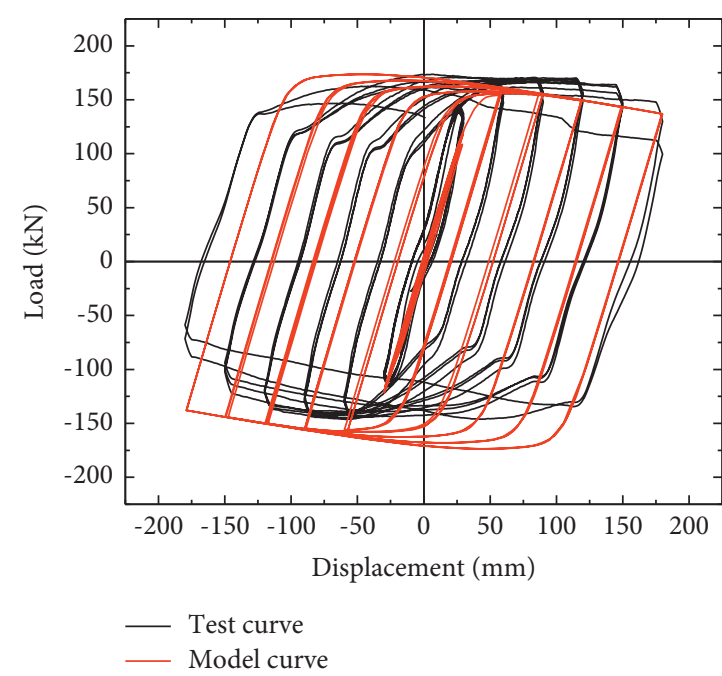

(a)

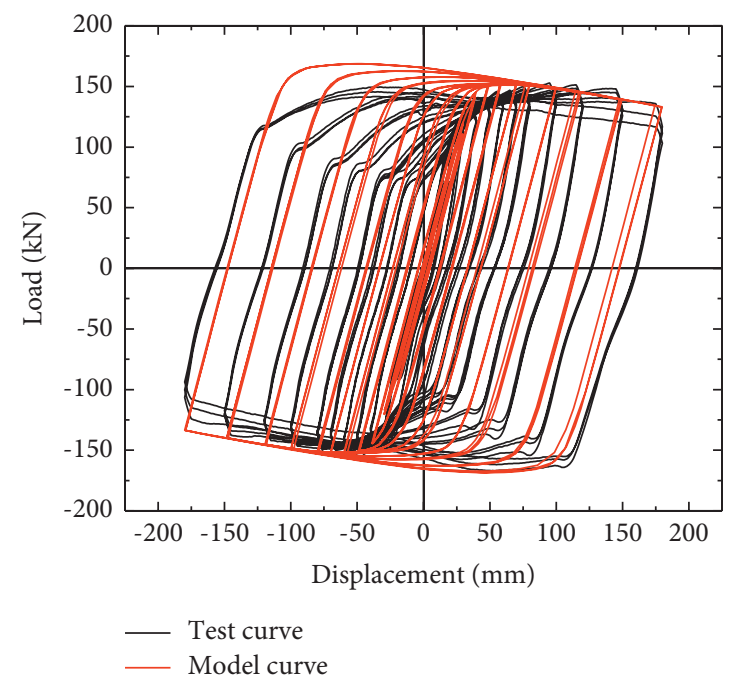

(b)

Figure 14: Comparison between the model curve and test curve. (a) SH-1. (b) SH-2.

4.2. Verification of Hysteresis Curve. The hysteresis curve drawn by the above hysteresis rule is compared with the experimental hysteresis curve, as shown in Figure 14, and the results show that they are consistent.

\section{Conclusions}

Based on the load-displacement hysteretic curve and skeleton curve obtained from the test, we establish a restoring force model suitable for the new type joints. This model mainly consists of three parts: the three-fold line skeleton model obtained from the test data, the specific calculation formula of stiffness degradation, and the mathematical description of hysteretic rules.

From the above results, it can be seen that the restoring force model on the joint of CTSRC column has the following characteristics:
(1) Under low cycle cyclic loading, the positive and reverse loading and unloading stiffness of the new type joint is equal to the initial stiffness of the joint in the elastic stage

(2) When the specimen enters the yield stage, the initial stiffness of positive and reverse loading and unloading gradually degenerates, and the degradation in the early stage is more obvious than that in the later stage

(3) Compared with the positive unloading stiffness and reverse unloading stiffness of the specimen, the stiffness degradation of positive loading stiffness and reverse loading stiffness is more obvious

The restoring force model can reflect the hysteretic behavior of the new type joint and can be used for 
elastoplastic seismic time-history analysis on the joint of CTSRC column.

\section{Data Availability}

The data used to support the findings of this study are available from the corresponding author upon request.

\section{Disclosure}

This is an open access article distributed under the Creative Commons Attribution License, which permits unrestricted use, distribution, and reproduction in any medium, provided the original work is properly cited.

\section{Conflicts of Interest}

The authors declare no potential conflicts of interest with respect to the research, authorship, and/or publication of this article.

\section{Acknowledgments}

This research was supported by the National Natural Science Foundation of China (No. 51408052), Youth Science and Technology Star Project of Shaanxi Province (No. 2016KJXX-51), Key Research and Development Plan of Shaanxi Province (No. 2018SF-354), and special fund for basic scientific research in Central Universities of Chang'an University (No. 300102289205).

\section{References}

[1] W. Ramberg and W. Osgood, "Description of steel stain curve by three parameters," National Advisory Committee for Aeronautics, Moffett Field, CA, USA, Technical Notes No: 902, 1943.

[2] P. Jennings, "Periodic response of a general yielding structure," Journal of Engineering Mechanical Division, vol. 90, no. 20 , pp. $131-165,1964$.

[3] R. Clough and S. Johnston, "Effect of stiffness degradation on earthquake ductility requirements," in Proceedings of the 2 nd Japan National Conference on Earthquake Engineering, pp. 227-232, Tokyo, Japan, September 1966.

[4] T. Takeda, M. A. Sozen, and N. N. Nielsen, "Reinforced concrete response to simulated earthquakes," Journal of the Structural Division, vol. 96, no. 12, pp. 2557-2572, 1970.

[5] C. Yan, D. Yang, Z. Ma, and J. Jia, "Hysteretic model of SRUHSC column and SRC beam joints considering damage effects," Materials and Structures, vol. 50, no. 1, 2017.

[6] Y. Zhang and S. Han, "Hysteretic model for flexure-shear critical reinforced concrete columns," Journal of Earthquake Engineering, vol. 22, no. 9, pp. 1639-1661, 2018.

[7] O. Yuka and I. Hideki, "Smooth hysteretic model of H-shaped steel beams," Ce/Papers, vol. 3, no. 3-4, pp. 145-150, 2019.

[8] Y. Zhang, G. Ma, S. Du, Y. Liu, Z. Li, and Y. F. Chen, "Hysteretic behavior and restoring force model of reinforced glazed hollow bead insulation concrete (GIC) columns," KSCE Journal of Civil Engineering, vol. 23, no. 7, pp. 30493065, 2019.

[9] Q. Hao, T. Motohide, T. Naoki, and S. Yu, "Monotonic and hysteretic model for $\mathrm{H}$-shaped beams incorporating deterioration behavior owing to the local buckling," ThinWalled Structures, vol. 157, Article ID 107016, 2020.

[10] Y. Wang, Y. Feng, D. Huang, Z. Huang, and Z. Chen, "Restoring force model of an energy-dissipation joint and nonlinear dynamic analysis of a hybrid frame," Journal of Building Engineering, vol. 32, Article ID 101762, 2020.

[11] H. Li, R. Li, C. Li, and D. Wang, "Development of hysteretic model with dynamic effect and deterioration for seismicperformance analysis of reinforced concrete structures," Journal of Structural Engineering, vol. 146, no. 10, 2020.

[12] Q. Xie, X. Zhao, X. Yao, W. Hao, and F. Hu, "Seismic behaviors of precast assembled bridge columns connected with prestressed threaded steel bar: experimental test and hysteretic model," Advances in Structural Engineering, vol. 23, no. 9, pp. 1975-1988, 2020.

[13] C. Wu, X. Liu, W. Pan, and B. Mou, "Restoring force model for modular prefabricated steel-reinforced concrete column to $\mathrm{H}$-shaped steel beam composite joints," Journal of Building Engineering, vol. 42, 2021.

[14] Z. Song, F. Yu, N. Zhang, and Y. Fang, "A model for predicting load-displacement hysteretic behavior of PVC-CFRP confined concrete column-ring beam interior joints under low cyclic loading," Composite Structures, vol. 265, 2021.

[15] X. Ni, S. Cao, and Y. Hou, "Hysteretic model of shear walls built with high-strength reinforcement," Structural Concrete, vol. 22, no. 3, pp. 1378-1395, 2021.

[16] X. Zhou, J. Liu, and S. Zhang, "Experimental study on seismic behavior of square steel tube confined steel reinforced concrete short columns," Journal of Building Structures, vol. 31, no. 7, pp. 49-55, 2010.

[17] J. Liu, X. Zhang, and S. Zhang, "Axial compression behavior of circular steel tube confined steel reinforced high strength concrete short columns," Journal of Building Structures, vol. 30, no. 2, pp. 242-248, 2009.

[18] X. Zhou and J. Liu, "Seismic behavior and strength of tubed steel reinforced- concrete(SRC) short columns," Journal of Constructional Steel Research, vol. 66, no. 1, pp. 28-36, 2010.

[19] Y. Dai, S. Nie, and T. Zhou, "Finite element analysis of hysteretic behavior of Square steel tube confined steel reinforced concrete column steel frame ring beam joint," Journal of Jilin University (Engineering and Technology Edition), vol. 48, no. 5, pp. 1426-1435, 2018.

[20] Y. Dai, S. Nie, and T. Zhou, "Seismic behavior of Circular steel tube confined $\mathrm{H}$ steel reinforced concrete column steel frame ring beam joint," Journal of South China University of Technology, vol. 47, no. 5, pp. 110-122, 2019.

[21] Y. Dai, S. Nie, and T. Zhou, "Shear capacity of circular steel tube confined H-SRC concrete column steel beam joint with ring beam," Journal of Jilin University (Engineering and Technology Edition), vol. 51, no. 3, pp. 977-988, 2021.

[22] Z. Guo and X. Lv, "Experimental study on the hysteretic model of RC columns with high axial compressive ratio," China Civil EngiNeering Journal, vol. 37, no. 5, pp. 32-38, 2004.

[23] G. Zhang, X. Lv, and B. Liu, "Study on resilience models of high-strength concrete frame columns," Engineering $\mathrm{Me}$ chanics, vol. 24, no. 3, pp. 83-90, 2004.

[24] China Construction Industry Press, Code for Seismic Test Methods of Buildings, China Construction Industry Press, Beijing, China, 2015.

[25] L. Zeng, Research on Seismic Behaviors and Design Method of Steel Reinforced High Strength and High Performance Concrete Frame Joints, Xi'an University of Architecture and Technology, Xi'an, China, 2008. 